\title{
Change of expansion characteristics of compacted soils used for dams in central Vietnam
}

\author{
Quang Thanh Truong ${ }^{1, *}$, Phan Ta $\mathrm{Le}^{1}$ and Thi Nhu Quynh Nguyen ${ }^{1}$ \\ ${ }^{1}$ Civil Engineering Department, University of Architecture Ho Chi Minh City, 196 Pasteur - Ward 6 - \\ District 3 - HCMC, Vietnam
}

\begin{abstract}
Most of the earth embankments in central Vietnam are usually built with clays. Some types of clays in this area are swollen. If they are used to build dams, it can be detrimental to the embankment. Based on the results of laboratory test analysis, the authors investigated swelling characteristics of some soil types in the study area and found that the swelling rate of soil increases with the compaction of the soil sample. When swelling under pressure in approaching water over time, the swelling coefficient of the soil decreases significantly. Thus, swelling clays can be used to make dams, but they must be put in the appropriate position for the purpose of not swelling freely.
\end{abstract}

\section{Introduction}

Expansive soils are encountered at some construction sites in the Central Vietnam. There are a lot of soil works built in Central Vietnam such as hydroelectric dams, hydraulic engineerings, transport infrastructures. The number of soil dams in this area occupies more than $80 \%$ of those in the whole country [1]. An attempt is usually made to avoid these soils as construction materials because of the difficulty in predicting the volume change characteristics; however, in many cases due to the immediate availability or the high cost of transporting other soil to the construction site, it is impossible or impractical to avoid using these materials.

Expansive soils that contain the clay mineral montmorillonite with claystones, sedimentary and residual soils absorb great amount of water. Swelling is related to water absorption of clay minerals. Soil swelling is the increasing in volume as it gets wet. In the swelling period, the volume expands but the cohesion decreases due to the low cohesion between soil particles. So it is clear that there are the disadvantages of these swelling soils when they attract and absorb water. The swelling soils shrink when they are dried lead to cracks appearing. Thus, water can permeate to the deeper soil layers through these cracks. The more water they absorb the more their volumes increase. This produces a cycle of shrinkage and swelling that causes the soil to undergo great amount of volume changes. This movement in the soil results in structural damages especially in lightweight structures such as sidewalks, driveways, basement floors [2].

\footnotetext{
*Corresponding author: xyztruongquangthanh@gmail.com
} 
The amount of swell generally increases with an increase in the plasticity index. The swelling potential depends on the type of clay mineral, crystal lattice structure, cation exchange capacity, ability of water absorption, density and water content [3].

There have been many researches related to swelling soil. This paper presents the changes of swelling characteristics of various compacted samples used to build dams in the Central Vietnam within the condition of the experienced samples are kept tightly and soaked in water as time elapses.

\section{Literature review}

Reddi and Inyang (2000) found that the mineralogy plays a very important role in soil characterization, particularly clays. The mineral composition of soil highly depends on the composition of parent rock from which soils are formed.

The laboratory test results on mineral components of clay samples used to dam in Central Vietnam prove that the mineral content in research regions changes significantly. The most important clay minerals include: Kaolinite, Illite and monmorillonite. Kaolinite content is in the range of $16 \%$ to $30 \%$ and monmorillonite is quite different between regions, from $3 \%$ to $12 \%$. The molecular structure of clay minerals is so complicated and clay minerals affect on soil swell [5].

The characteristics of swelling force and the relationship among main factors: initial water content, dry density and test time are studied in the paper. There are several conclusions shown as follows: Swelling force decreases with increasing initial water content and the relationship between them can be expressed by power exponent. 1 Swelling force is deeply affects by dry density, swelling force rapidly increases with increasing dry density, and the relationship is increasing index function [6].

Lots of researchers studied on dry density in detail, one of the most important factors of swelling force, and put forward almost the same conclusions. Laboratory experiment on compacted swelling soil of GMZ01 by Ye Wei-ming and T.SCHANZ [7] shows the exponential function relationship between swelling force and dry density and the discontinuity of swelling force versus dry density curve. The function is shown as follow:

$$
\mathrm{p}_{\mathrm{s}}=\mathrm{a} \exp \left(\mathrm{b} . \rho_{\mathrm{d}}\right)
$$

Where: $a$ and $b$ are constants, $\rho d$ is dry density.

In the initial test stage, along with water soaking through swelling rock and soil, the internal structure of swelling rock varies constantly, swelling force caused by volume constraint and swelling speed becomes faster and faster. Soon after, the internal structure of swelling rock becomes more stable, the increase rate of swelling force decelerates gradually, and the absorption rate also slows down. At last, swelling soil reaches saturation, swelling force and internal structure tend to be stable, and test sample reaches slow swelling stage and water absorption tends to be ease. So there are several stages during the change process of swelling force. The swelling force increases rapidly in initial stage, until reaches certain value and then slowly increases to stable value [8].

In addition to soil composition, swelling properties are dependent upon the dry density of the soil, initial moisture content, and availability and properties of water [9]. One of the most important of these factors is dry density. This is explained by considering the number of soil particles within a given volume. The more particles present in a unit volume, the greater will be the surface area available for adsorption of water, as a result, the swelling potential will be greater. This belief is supported by Leonards [10] in his statement," it was found that swelling in the presence of water, at a specified confining pressure, increases as the amount of compaction increases." The increased compaction would result in more clay particles occupying the same volume. 
Some investigators studied the swelling characteristics of expansive soils after repeatedly wetting-drying cycles. Guney (2007) concluded that swelling potential increased with the number of cycles. Cyclic wetting-drying resulted in particle aggregation. The reduction in clay content and the plasticity index values of the soils after the increasing number of cycles. This inevitably caused reduction in the swelling characteristics [4].

There have been many researches to get over the disadvantages of swelling soil as damming recently. The paper [11] provides detail information about the identifying the black cotton soil, about its swell - shrink behavior, factors affecting swelling and shrinkage, reasons of swell - shrink behavior and the controlling measures. The author has listed three methods to resolve this problem of swelling and shrinkage of clayey soil. They also described their conclusion that control of the swell-shrink behavior can be accomplished in several ways, for example by Replace existing expansive soil with non-expansive soil, Maintain constant moisture content and Improve the expansive soils by stabilization from which stabilization is a better option to choose as per economic and improvisational consideration.

Many researchers have made an attempt with the chemical stabilization technique, it has gained prominence due to its easy applicability and adaptability. Flash is freely available waste product which has little cementing property can be used for altering the characteristics of expansive soil. The main objective of this work is to study the swelling properties of the expansive subgrade soil treated with chemicals like Magnesium Chloride $(\mathrm{MgCl} 2)$, Aluminum Chloride $(\mathrm{AlCl} 3)$ and also by adding flyash in varying percentages. The swelling properties of the collected expansive soil samples were determined based on the parameters like Free Swell Index, Swell Potential and Swell Pressure. The results obtained from the experimental study indicate that the measured Free Swell, Swell Potential and Swelling Pressure are reduced substantially with the increasing percent of chemicals and flyash and remain stable after reaching certain concentration [12].

\section{Methodology and materials}

Collecting some kinds of soil sample

1. Establishing properties of soil sample

2. Preparing soil sample with different compactness coefficients in:

- $\quad$ soil sample rings

- hard PVC tubes

3. Free swell testing (soil sample rings)

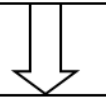

Soaking prepared sample tubes in water tank - saturating the soil sample
Determining the characteristics of the soil:

1. Particle size distributions

2. Specific gravity

3. Atterberg's limits:

- Plastic limit

- Liquid limit

- Plasticity index

4. Modified proctor test:

- Optimum moisture

- Maximum dry density

Swell test for sample tubes at specified time points. Free swell index

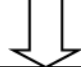

Observations \& Interpretation

Fig. 1. Methodology. 
In order to build dams in Central Vietnam, some types of soils that are used in the experiment as following:

Type 1: Soils originated from granite, which are used to build Thuan Ninh dam - Binh Dinh Province

Type 2: Soils formed from Siltstone, which are used to build Song Sat dam - Ninh Thuan province

Type 3: Soils formed from Baslt. Basaltic soils, which are used to build DakRtih hydropower - Daklak province.

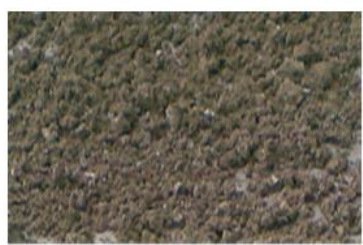

Soil Type 1

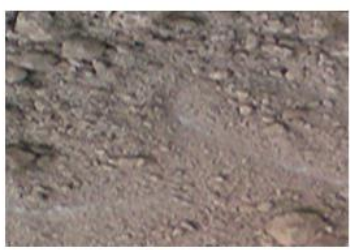

Soil Type 2

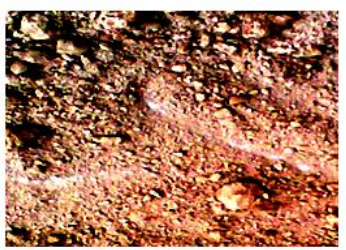

Soil Type 2

Fig. 2. Three types of soil in the experiment.

The results of particle size distribution analysis performed on the soil, physical properties and Modified proctor testare shown in Table 1.

Table 1. Engineering property values of three types of soil.

\begin{tabular}{|c|c|c|c|c|c|c|c|}
\hline \multirow{2}{*}{\multicolumn{4}{|c|}{ Physical properties }} & \multirow{3}{*}{$\begin{array}{c}\text { Unit } \\
\%\end{array}$} & \multicolumn{3}{|c|}{ Type of soil } \\
\hline & & & & & \multirow{2}{*}{$\begin{array}{c}\text { Type } 1 \\
-\end{array}$} & \multirow{2}{*}{$\begin{array}{c}\text { Type } 2 \\
-\end{array}$} & \multirow{2}{*}{$\begin{array}{c}\text { Type } 3 \\
-\end{array}$} \\
\hline \multirow{11}{*}{$\begin{array}{l}\text { The } \\
\text { results of } \\
\text { grain size } \\
\text { analysis } \\
\text { performed } \\
\text { on the soil }\end{array}$} & \multirow{3}{*}{ Gravel } & coarse & $10 \div 6$ & & & & \\
\hline & & medium & $6 \div 4$ & $\%$ & 0.1 & - & 0.3 \\
\hline & & fine & $4 \div 2$ & $\%$ & 5 & 0.8 & 1.1 \\
\hline & \multirow{4}{*}{ Sand } & $\begin{array}{c}\text { very } \\
\text { coarse }\end{array}$ & $2 \div 1$ & $\%$ & 12.2 & 2.8 & 0.9 \\
\hline & & coarse & $1 \div 0.5$ & $\%$ & 5 & 4 & 1.6 \\
\hline & & medium & $0.5 \div 0.25$ & $\%$ & 5 & 7 & 2.8 \\
\hline & & fine & $0.25 \div 0.1$ & $\%$ & 10 & 8 & 9.8 \\
\hline & \multirow{3}{*}{ Silt } & coarse & $0.1 \div 0.05$ & $\%$ & 17.9 & 12 & 28.5 \\
\hline & & medium & $0.05 \div 0.01$ & $\%$ & 10.8 & 13 & 11.7 \\
\hline & & fine & $0.01 \div 0.005$ & $\%$ & 11.9 & 15 & 7.2 \\
\hline & \multicolumn{2}{|c|}{ Clay } & $<0.005$ & $\%$ & 22.2 & 37.4 & 36.2 \\
\hline \multicolumn{4}{|c|}{ Specific gravity $-\mathrm{G}_{\mathrm{s}}$} & - & 2.69 & 2.68 & 2.78 \\
\hline \multicolumn{4}{|c|}{ Liquid Limit - wL } & $\%$ & 35.5 & 37.9 & 74.31 \\
\hline \multicolumn{4}{|c|}{ Plastic Limit - WP } & $\%$ & 18 & 22.69 & 48.63 \\
\hline \multicolumn{4}{|c|}{ Plasticity Index - IP } & - & 17.4 & 15.01 & 25.68 \\
\hline \multicolumn{4}{|c|}{ Maximum dry density - $\rho_{\mathrm{dmax}}$} & $\mathrm{g} / \mathrm{cm}^{3}$ & 18.4 & 18.6 & 14.1 \\
\hline \multicolumn{4}{|c|}{ Optimum moisture content - $\mathrm{w}_{\mathrm{opt}}$} & $\%$ & 13 & 14 & 37 \\
\hline
\end{tabular}

Volume expansion rate of soil and expansive soil classification.

Laboratory test method for determination of expansion characteristics of soil according to Vietnamese standard TCVN 8719:2012 [14].

Volume expansion rate of soil (RN) is determined by the changes of sample height as following equation: 


$$
R^{N}=\frac{h_{f}-h_{i}}{h_{i}}(\%)
$$

Where: hf, hi - final height and initial height of sample, respectively. If the sample swells freely, there is freely swelling rate. Otherwise, that is known as pressured swelling.

Classification of expansive soil is shown in Table 2.

Table 2. Soil swelling classification according to [14].

\begin{tabular}{|c|c|}
\hline Free swelling rate- $\mathrm{R}^{\mathrm{N}}(\%)$ & Classification \\
\hline $\mathrm{R}^{\mathrm{N}} \leq 4$ & Not swelling - (Non) \\
$4<\mathrm{R}^{\mathrm{N}} \leq 8$ & Weak swelling - (Low) \\
$8<\mathrm{R}^{\mathrm{N}} \leq 12$ & Medium swelling - (Mid) \\
$\mathrm{R}^{\mathrm{N}}>12$ & Strong swelling - (High) \\
\hline
\end{tabular}

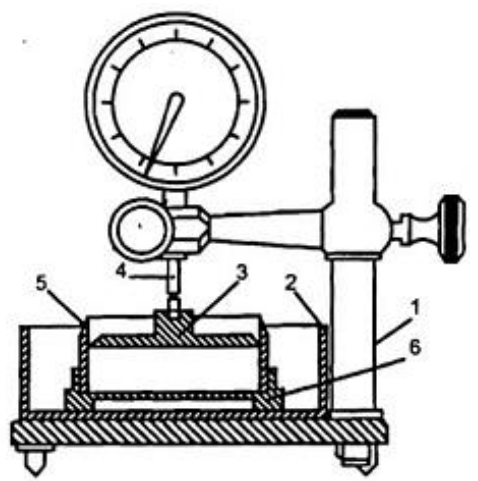

Annotation:

1. Dial gauge stand

2. water box

3. Pitston

4. Dial gauge

5. Soil sample ring

6. Ring box

Fig. 3. Swelling test equipment.

The research [1] shows that some kinds of soils used to build dams in central of Vietnam are not swelling in nature $(\mathrm{RN}<4 \%)$. However, that sample is prepared after its structure collapsed makes its swelling property is clearly shown.

Preparing samples method and Experiment.

Samples are prepared according to proctor densities ( $\rho$ dmax; wopt) of 3 types of soils listed in Table 3. Dry densities of samples are made with compactness coefficient $(\mathrm{K})$ : 0.92 , $0.95,0.98$ respectively. Moisture content of each sample (wcb) is optimum moisture content (wopt) as compacting.

Samples are prepared in hard PVC tubes. These tubes are $5 \mathrm{~mm}$ in thickness, $30 \mathrm{~cm}$ in length and $114 \mathrm{~mm}$ in inner diameter. Ends of tube are glued with covers. In order to remain saturated soils while soaking, some holes, $2 \mathrm{~mm}$ in diameter, are drilled on tube body and covers.
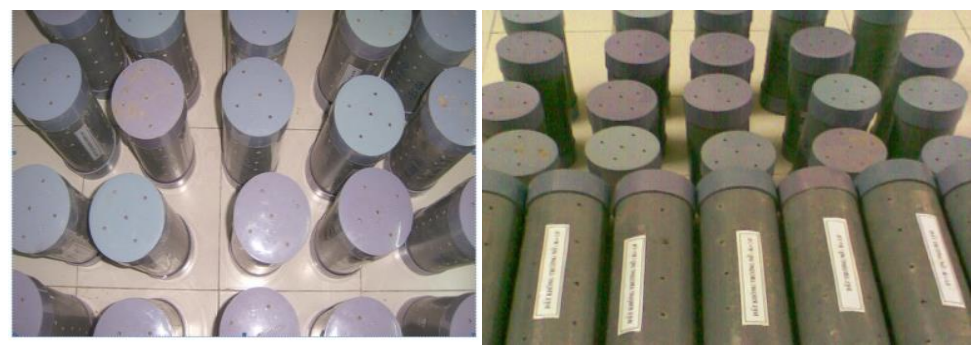

Fig. 4. Compacted soil sample in tubes. 
At the Geology Engineering Laboratory in Southern Institute of Water Resources Research, prepared samples are soaked in water tank. These samples are tested right after prepared and after soaked in water in $2,6,12,18$ months respectively for the purpose of considering the changes of swelling coefficient during that time.

According to the experiment results, free swelling rate $(\mathrm{RN})$ of each sample soaked in water are obtained. These free swelling rates corresponding to time are collected and presents in a table. Besides, the following index are used in order to evaluate the rate of increasing or decreasing in swelling rate. Swelling reduction rate:

$$
\eta_{R N}=\frac{R_{t}^{N}-R_{0}^{N}}{R_{0}^{N}}
$$

Where: $R_{0}^{N}$ - Free swelling rate of saturated soils (after 2 months soaking in water)

$R_{t}^{N}$ - Free swelling rate of soils after t months soaking in water (2 months soaking)

The value $\eta_{R N}$ of each type of soils corresponding to compactness coefficient $(K)$ and soaking time (t) are listed in table in section 4.
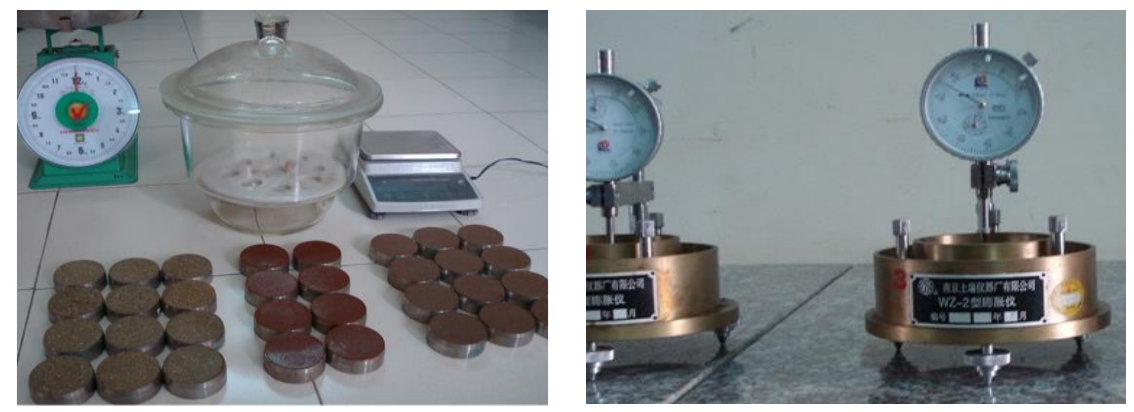

Fig. 5. Preparation for experiment.

\section{Experiment results}

Structure of Soils in research regions are collapsed then these samples are prepared into soil sample rings, tubes and soaked in water. These samples have different compact coefficients. The experiment of soil swell corresponding to time is conducted.

\subsection{Compacted soil at Thuan Ninh dam - Binh Dinh province (Soil type 1)}

After preparing samples in soil sample rings, sample moisture is the optimum moisture $\mathrm{w}_{\mathrm{opt}}$ $=13 \%$, dry density of sample $\rho_{\mathrm{d}}=\mathrm{K}$. $\rho_{\mathrm{dmax}}$ (maximum dry density is $1.84 \mathrm{~g} / \mathrm{cm}^{3}$, compactness coefficient K of prepared samples are $0.92,0.95,0.98)$. The results of soil swell are listed in Table 3 and presented in Figure 5.

Table 3. Free swelling rate $-\mathrm{R}^{\mathrm{N}}(\%)$ of soils at Thuan Ninh dam- Binh Dinh Province.

\begin{tabular}{|c|c|c|c|}
\hline \multirow{2}{*}{$\begin{array}{c}\text { Time } \\
\text { (Hours) }\end{array}$} & \multicolumn{3}{|c|}{ Free swelling rate $-\mathrm{R}^{\mathrm{N}}(\%)$} \\
\cline { 2 - 4 } & $\mathrm{K}=0.92$ & $\mathrm{~K}=0.95$ & $\mathrm{~K}=0.98$ \\
\hline 0 & 0 & 0 & 0 \\
\hline 0.5 & 3.1 & 6.2 & 8.1 \\
\hline 1.0 & 6.2 & 9.1 & 12.3 \\
\hline 2 & 8.1 & 11.1 & 13.5 \\
\hline 4 & 9.0 & 12.5 & 14.5 \\
\hline 8 & 9.5 & 13.1 & 15.2 \\
\hline
\end{tabular}




\begin{tabular}{|c|c|c|c|}
\hline 32 & 9.7 & 13.2 & 15.4 \\
\hline 56 & 9.8 & 13.3 & 15.5 \\
\hline 80 & 9.9 & 13.4 & 15.6 \\
\hline 104 & 10.0 & 13.5 & 15.7 \\
\hline 152 & 10.1 & 13.6 & 15.7 \\
\hline 224 & 10.2 & 13.6 & 15.7 \\
\hline 272 & 10.2 & 13.6 & 15.7 \\
\hline
\end{tabular}

Samples are prepared into tubes with compactness coefficient $\mathrm{K}$ as $0.92,0.95,0.98$ and soaked in water. At due time, samples are taken and put into soil sample rings to conduct the swelling experiment. The results of swell corresponding to time are listed in Table 4 and shown in Figure 6.

Table 4. Free swelling rate corresponding to time $\mathrm{R}^{\mathrm{N}}(\%)$ of soils at Thuan Ninh - Binh Dinh Province.

\begin{tabular}{|c|c|c|c|}
\hline \multirow{2}{*}{$\begin{array}{c}\text { Time } \\
\text { (months) }\end{array}$} & \multicolumn{3}{|c|}{ Free swelling rate $-\mathrm{R}^{\mathrm{N}}(\%)$} \\
\cline { 2 - 4 } & $\mathrm{K}=0.92$ & $\mathrm{~K}=0.95$ & $\mathrm{~K}=0.98$ \\
\hline 2 & 3.6 & 3.80 & 4.00 \\
\hline 6 & 3.4 & 3.62 & 3.84 \\
\hline 12 & 3.3 & 3.50 & 3.70 \\
\hline 18 & 3.2 & 3.40 & 3.61 \\
\hline
\end{tabular}

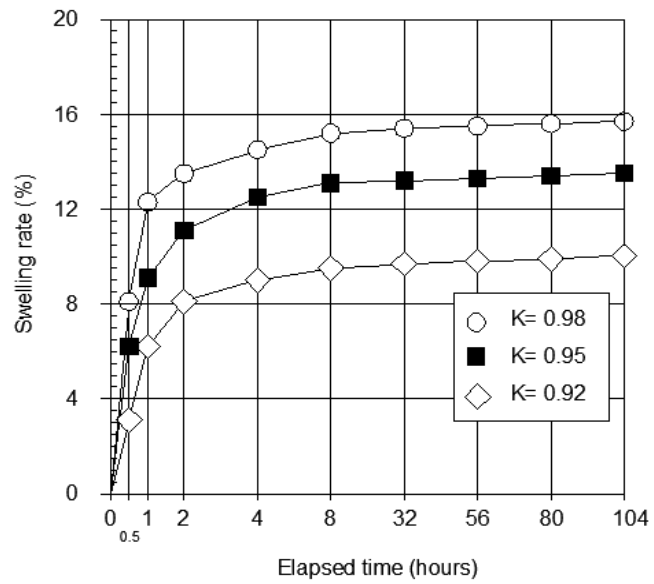

Fig. 6. Plot of Free swelling rate vs. Time from the calculation shown in Table 3 (Soil Type 1).

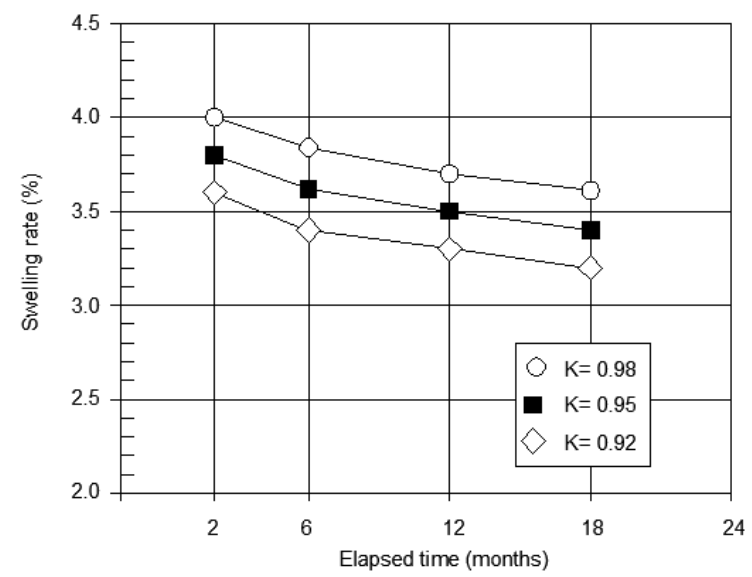

Fig. 7. Plot of Free swelling rate vs. Time from the calculation shown in Table 4 (soil Type 1). 
The swelling reduction rate is calculated as equation (2), its results are listed in Table 5 and presented in Figure 7.

Table 5. The swelling reduction rate of soils at Thuan Ninh dam - Binh Dinh province.

\begin{tabular}{|c|c|c|c|c|}
\hline $\begin{array}{c}\text { The compactness } \\
\text { coefficient (K) }\end{array}$ & $\begin{array}{c}\text { Density of } \\
\text { prepared soil } \\
\rho_{\mathrm{d}}\left(\mathrm{g} / \mathrm{cm}^{3}\right)\end{array}$ & $\begin{array}{c}\text { Soaking time } \\
\text { (months) }\end{array}$ & $\begin{array}{c}\text { Free swelling rate } \\
\mathrm{R}^{\mathrm{N}}(\%)\end{array}$ & $\begin{array}{c}\text { Swelling } \\
\text { reduction rate } \\
\eta_{\mathrm{RN}}(\%)\end{array}$ \\
\hline & & 2 & 3.60 & \\
0.92 & 1.693 & 12 & 3.40 & 5.56 \\
& & 18 & 3.30 & 8.33 \\
& & 2 & 3.20 & 11.11 \\
\hline \multirow{3}{*}{0.95} & 1.748 & 12 & 3.80 & 4.74 \\
& & 18 & 3.62 & 7.89 \\
& & 2 & 3.40 & 10.53 \\
\hline & 1.803 & 6 & 4.00 & 4.00 \\
& & 12 & 3.84 & 7.50 \\
\hline
\end{tabular}

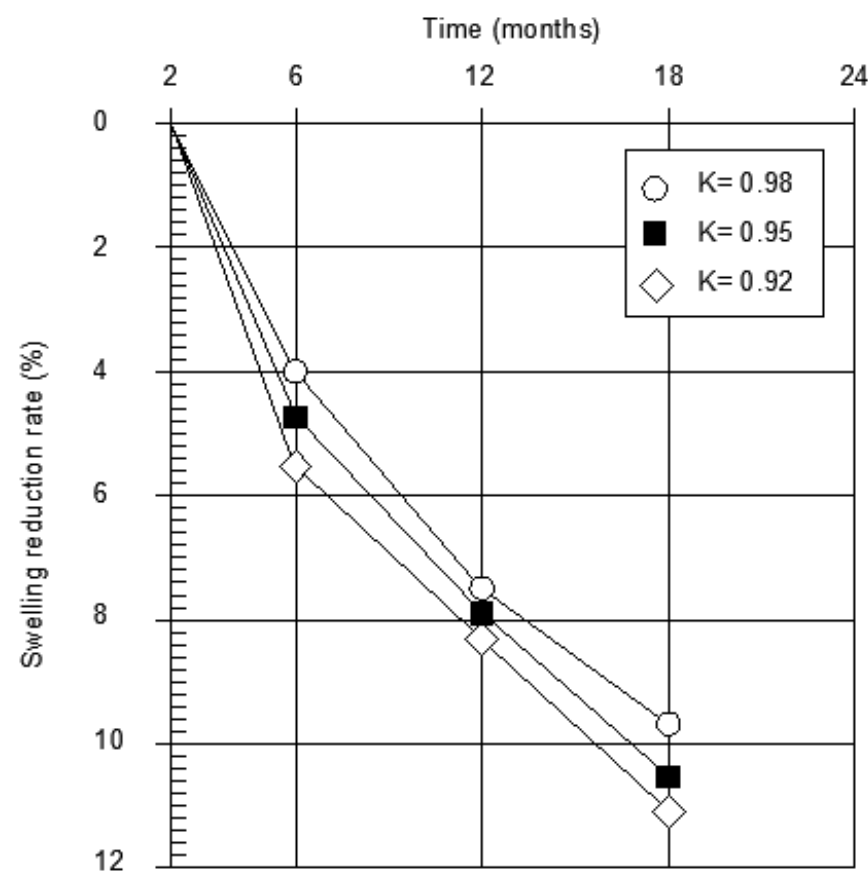

Fig. 8. Plot of swelling reduction rate vs. Time from the calculation shown in Table 5 (soil Type 1).

\subsection{Compacted soil at Song Sat dam - Ninh Thuận province (Soil type 2)}

After preparing samples into soil sample rings, sample moisture is the optimum moisture $\mathrm{w}_{\mathrm{opt}}=14 \%$, dry density of sample $\rho_{\mathrm{d}}=\mathrm{K} . \rho_{\mathrm{dmax}}$ (maximum dry density is $1.86 \mathrm{~g} / \mathrm{cm}^{3}$, compactness coefficient $\mathrm{K}$ of prepared samples are $0.92,0.95,0.98)$. The results of soil swell are listed in Table 6. 
Table 6. Free swelling rate - $\mathrm{R}^{\mathrm{N}}(\%)$ of compacted soils at Song Sat dam - Ninh Thuận Province.

\begin{tabular}{|c|c|c|c|}
\hline \multirow{2}{*}{$\begin{array}{c}\text { Time } \\
\text { (hours) }\end{array}$} & \multicolumn{3}{|c|}{ Free swelling rate $-\mathrm{R}^{\mathrm{N}}(\%)$} \\
\cline { 2 - 4 } & $\mathrm{K}=0.92$ & $\mathrm{~K}=0.95$ & $\mathrm{~K}=0.98$ \\
\hline 0 & 0 & 0 & 0 \\
\hline 0.5 & 0 & 0 & 0 \\
\hline 1.0 & 2.05 & 2.24 & 2.49 \\
\hline 2 & 2.07 & 2.27 & 2.41 \\
\hline 4 & 2.07 & 2.27 & 2.41 \\
\hline 8 & 2.07 & 2.27 & 2.41 \\
\hline
\end{tabular}

Samples are prepared into tubes with compactness coefficient $\mathrm{K}$ as $0.92,0.95,0.98$ and soaked in water. At due time, samples are taken and put into soil sample rings to conduct the swelling experiment. The results of swell corresponding to time are listed in Table 7 and shown in Figure 7.

Table 7. Free swelling rate corresponding to time $\mathrm{R}^{\mathrm{N}}(\%)$ of soils at Song Sat dam - Ninh Thuan Province.

\begin{tabular}{|c|c|c|c|}
\hline \multirow{2}{*}{$\begin{array}{c}\text { Time } \\
\text { (months) }\end{array}$} & \multicolumn{3}{|c|}{ Free swelling rate $-\mathrm{R}^{\mathrm{N}}(\%)$} \\
\cline { 2 - 4 } & $\mathrm{K}=0.92$ & $\mathrm{~K}=0.95$ & $\mathrm{~K}=0.98$ \\
\hline 2 & 1.21 & 1.24 & 1.27 \\
\hline 6 & 1.15 & 1.17 & 1.19 \\
\hline 12 & 1.15 & 1.17 & 1.19 \\
\hline 18 & 1.15 & 1.17 & 1.19 \\
\hline
\end{tabular}

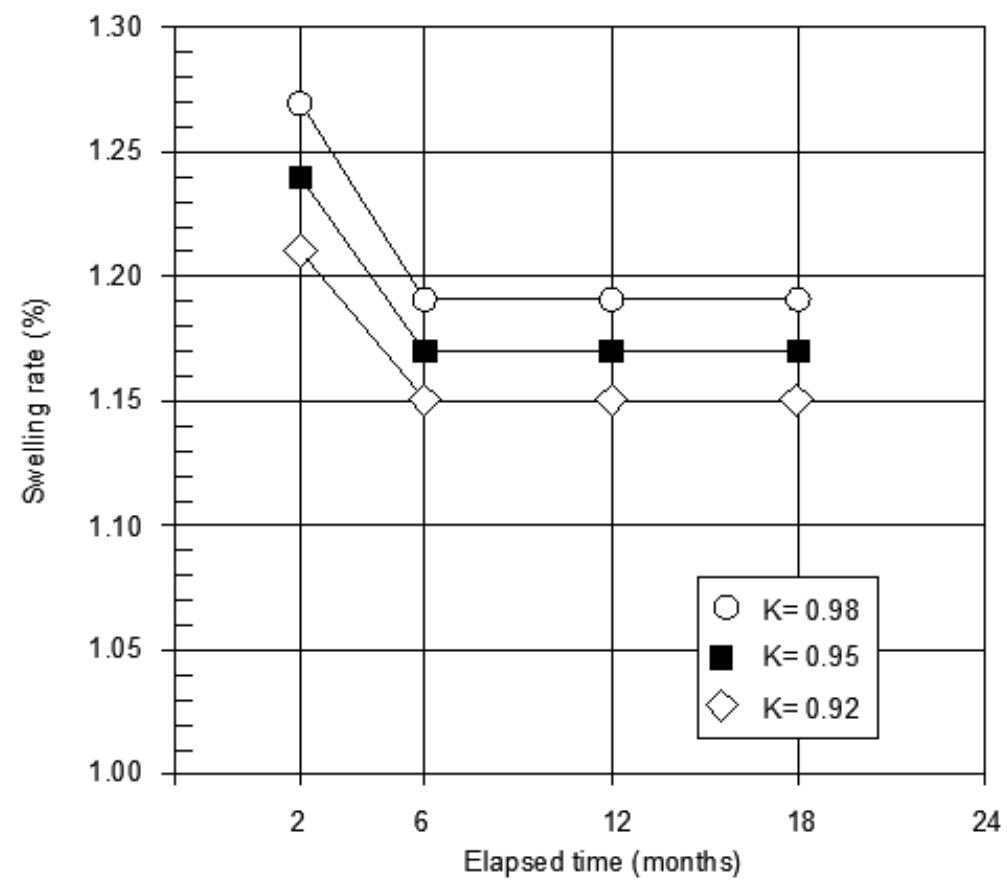

Fig. 9. Plot of Free swelling rate vs. Time from the calculation shown in Table 7 (soil Type 2).

The swelling reduction rate is calculated as equation (2), its results are listed in Table 8 and presented in Figure 9. 
Table 8. The changes of free swelling rate of soils at Song Sat dam - Ninh Thuan province.

\begin{tabular}{|c|c|c|c|c|}
\hline $\begin{array}{c}\text { Compactness } \\
\text { coefficient } \\
(\mathrm{K})\end{array}$ & $\begin{array}{c}\text { Density of } \\
\text { prepared sample } \\
\rho_{\mathrm{d}}\left(\mathrm{g} / \mathrm{cm}^{3}\right)\end{array}$ & $\begin{array}{c}\text { Soaking time } \\
(\text { months })\end{array}$ & $\begin{array}{c}\text { Free swelling } \\
\text { rate } \\
\mathrm{R}^{\mathrm{N}}(\%)\end{array}$ & $\begin{array}{c}\text { Swelling reduction } \\
\text { rate } \\
\eta_{\mathrm{RN}}(\%)\end{array}$ \\
\hline & & 2 & 1.21 & 4.96 \\
0.92 & 1.71 & 6 & 1.15 & 4.96 \\
& & 12 & 1.15 & 4.96 \\
\hline & & 2 & 1.15 & 5.65 \\
0.95 & 1.77 & 12 & 1.24 & 5.65 \\
& & 18 & 1.17 & 5.65 \\
\hline & & 2 & 1.17 & 6.29 \\
0.98 & & 6 & 1.27 & 6.29 \\
& & 12 & 1.19 & 6.29 \\
\hline
\end{tabular}

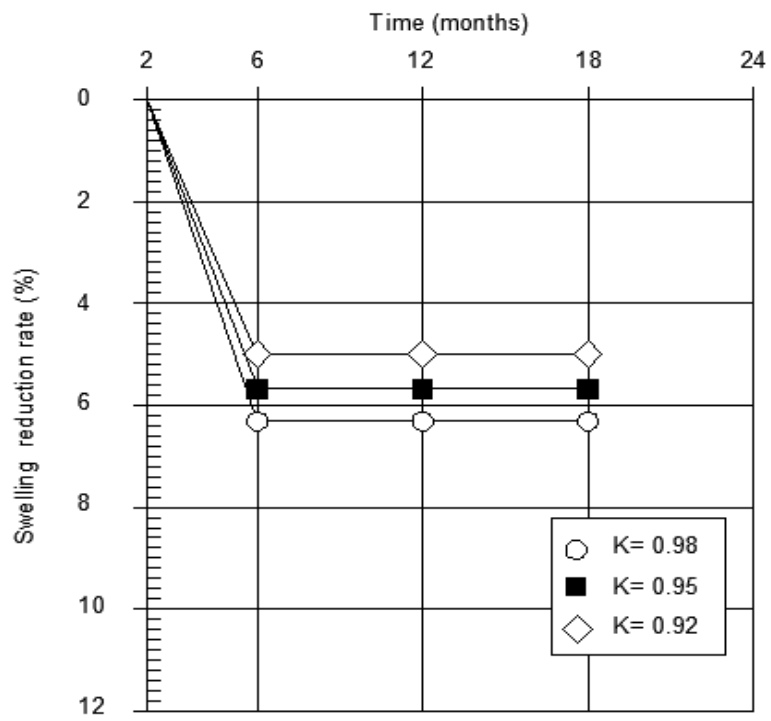

Fig. 10. Plot of swelling reduction rate vs. Time from the calculation shown in Table 8 (soil Type 2).

\subsection{Compacted soil at Dakr'Tih dam - Daklak province (Soil type 3)}

After preparing samples into soil sample rings, sample moisture is the optimum moisture $\mathrm{w}_{\mathrm{opt}}=14 \%$, dry density of sample $\rho_{\mathrm{d}}=\mathrm{K}$. $\rho_{\mathrm{dmax}}$ (maximum dry density is $1.41 \mathrm{~g} / \mathrm{cm}^{3}$, compactness coefficient $\mathrm{K}$ of prepared samples are $0.92,0.95,0.98)$. The results of soil swell are listed in Table 9.

Table 9. Free swelling rate $-\mathrm{R}^{\mathrm{N}}(\%)$ of soils at Dakr'Tih dam - Daklak Province.

\begin{tabular}{|c|c|c|c|}
\hline \multirow{2}{*}{$\begin{array}{c}\text { Time } \\
\text { (hours) }\end{array}$} & \multicolumn{3}{|c|}{ Free swelling rate- $\mathrm{R}^{\mathrm{N}}(\%)$} \\
\cline { 2 - 4 } & $\mathrm{K}=0.92$ & $\mathrm{~K}=0.95$ & $\mathrm{~K}=0.98$ \\
\hline 0 & 0 & 0 & 0 \\
\hline 0.5 & 0 & 0 & 0 \\
\hline 1.0 & 0 & 0 & 0.06 \\
\hline 2 & 0.04 & 0.05 & 0.06 \\
\hline 4 & 0.04 & 0.05 & 0.06 \\
\hline 8 & 0.04 & 0.05 & \\
\hline
\end{tabular}


Samples are prepared into tubes with compactness coefficient $\mathrm{K}$ as $0.92,0.95,0.98$ and soaked in water. At due time, samples are taken and put into soil sample rings to conduct the swelling experiment. The results of swell corresponding to time are listed in Table 10.

Table 10. Free swelling rate corresponding to time- $\mathrm{R}^{\mathrm{N}}(\%)$ of soils at Dakr'tihn dam - Daklak Province.

\begin{tabular}{|c|c|c|c|}
\hline \multirow{2}{*}{$\begin{array}{c}\text { Time } \\
\text { months })\end{array}$} & $\mathrm{3}$ & \multicolumn{3}{|c|}{ Free swelling rate $-\mathrm{R}^{\mathrm{N}}(\%)$} \\
\cline { 2 - 4 } & $\mathrm{K}=0.92$ & $\mathrm{~K}=0.95$ & $\mathrm{~K}=0.98$ \\
\hline 2 & 0 & 0 & 0 \\
\hline 6 & 0 & 0 & 0 \\
\hline 12 & 0 & 0 & 0 \\
\hline 18 & 0 & 0 & 0 \\
\hline
\end{tabular}

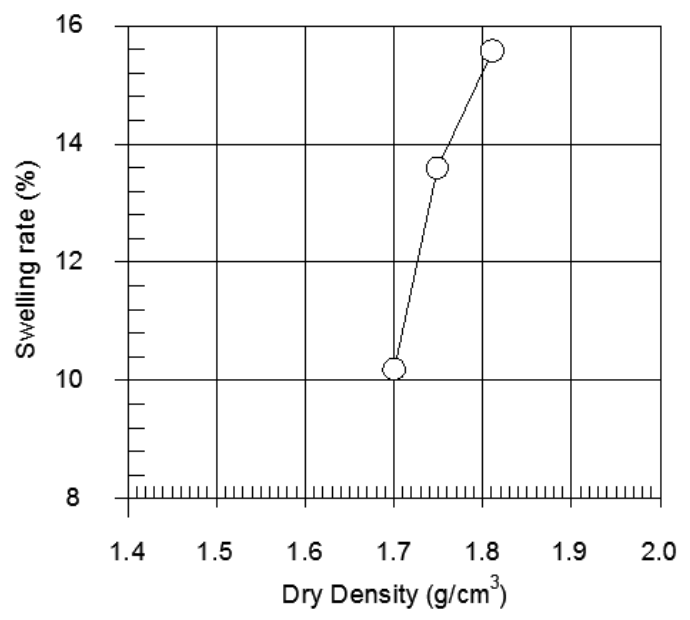

Fig. 11. Plot of Free swelling rate vs. Dry density (Soil Type 1).

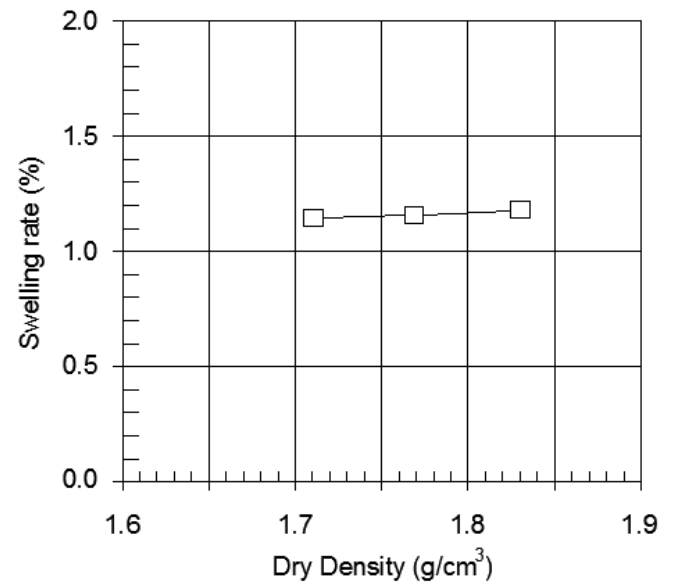

Fig. 12. Plot of Free swelling rate vs. Dry density (Soil Type 2). 


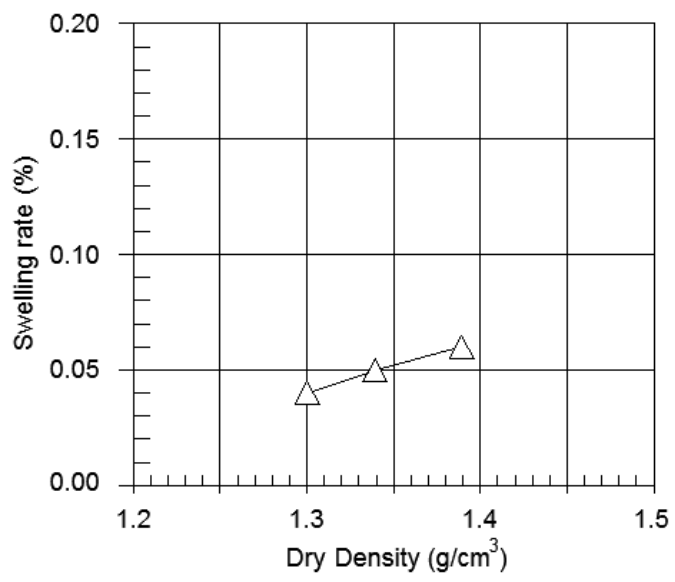

Fig. 13. Plot of Free swelling rate vs. Dry density (Soil Type 3).

\section{Discussion}

- The results of free swelling experiment of three of soils prepared with dry density $\gamma_{\mathrm{d}}=$ $\mathrm{K} . \gamma_{\mathrm{dmax}}$, optimum moisture content $\mathrm{w}_{\mathrm{cb}}=\mathrm{w}_{\mathrm{opt}}$. Results listed in Table 3, 6,9 are presented in Figure 10, Figure 11, Figure 12:

- With compactness coefficient $\mathrm{K}=0.92 \div 0.95$, free swelling rate of samples from Song Sat dam and Dark'tih dam are less than $4 \%$. Therefore, the swells of these samples are weak.

- Samples from Thuan Ninh dam are medium swell $\left(\mathrm{R}^{\mathrm{N}}=10,2 \%\right)$ when their compactness coefficients $\mathrm{K}$ are 0.92 and they swell strongly $\left(\mathrm{R}^{\mathrm{N}}>12 \%\right)$ when their compactness coefficients $\mathrm{K}$ are at least 0.95 . Therefore, the swelling rate of clays depends on compactness coefficient $\mathrm{K}$ or initial dry density of sample. The initial dry density used in designing dam is at least $0.95 \gamma_{\mathrm{dmax}}$. When clay soil used to dam is swelling, its characteristics must be limited.

- Samples with $\rho_{\mathrm{d}}=\mathrm{K} . \rho_{\mathrm{dmax}} ; \mathrm{w}_{\mathrm{cb}}=\mathrm{w}_{\mathrm{opt}}$ are prepared from 3 kinds of soils above. Although samples are prepared in hard PVC tubes with holes, they do not swell freely when soaking in water. They must swell under pressure. After doing experiment, the swelling rate $\left(\mathrm{R}^{\mathrm{N}}\right)$ of soils soaked in water from 2 months to 18 months are shown in table 4, table 7 and table 10 . The swelling rate of all kinds of soils reduces when soils swell in pressured tube in water tank as time elapses. Especially, the swelling rate of all samples from Thuan Ninh dam prepared with $\rho_{\mathrm{c}} \geq 0.95 \rho_{\mathrm{dmax}}, \mathrm{w}_{\mathrm{cb}}=\mathrm{w}_{\mathrm{opt}}$ are above $12 \%$ (Table 3 ). It can be explained that soils swell strongly. However, after soaked in water in 6 months, their all swell rate are less than $4 \%$. It means that the swelling process completed or soils do not swell. That the swell of samples prepared in tube in elapsed time reduce is as following reasons:

- When soaking samples in water, the moister content of sample increases gradually in period of elapsed time. When sample is taken out of tube to experiment, its moisture is greater than its initial moisture. Although samples are prepared with the same dry density, their swelling rate decrease in the condition of pressure due to the increasing of moisture.

- In the condition of pressured swell, the structures of samples gradually restore. These experiment results are compatible with the researches introduce in [13] such as: soil swells are affected by structures of soils, samples prepared with the same dry density, but the swelling rate decrease. 


\section{Conclusions}

A soil sample at a given dry density has a definite potential for swelling. For swelling soils, the rate of swelling increases with the compaction of the soil sample. When swelling under pressure in approaching water over time, the rate of swelling of the soil decreases significantly. It can be concluded that, swelling clay soil can be dammed, but the location of damming must be concerned with the aim of not having free swell.

\section{References}

1. Le Xuan Roanh, Construction of the dam in the central region with special embankment soil, PhD Thesis (Water Resources University, Vietnam, 2002)

2. M. Mokhtari, M. Dehghani, Swell Shrink Behavior of Expansive Soils, Damage and Controlll. EJGE, 12 (2012)

3. T. Tran, Study on the change of the soils properties of dams in the central Vietnam. Research topic of science and technology (2006)

4. S. Tawfiq, Z. Nalbantoglu, Swell-shrink behavior of expansive clays, 2nd International Conference on New Developments in Soil Mechanics and Geotechnical Engineering (2009)

5. Vietnam Irrigation Construction Consultancy Corporation. Report on the study of swelling, shrinkage and disintegration of material dams of the Ngan Truong Reservoir (Hanoi, 2010)

6. ZHU Xunguo, Research on the Characteristics of Swelling Force of Unsaturated Swelling Rock and Soil. International Conference on Electric Technology and Civil Engineering (ICETCE) (Lushan, China, 2011)

7. Ye Weimin, T. Schanz, Qian Lixin, Chinese Journal Of Rock Mechanics And Engineering 26(S2), 3861-3866 (2007)

8. X. Yun, C. Zhenghan, S. Shuguo, Rock and soil mechanics 28(8), 1636-1643 (2007)

9. J.V. Parcher, P.-C. Liu, Proceedings of the American Society of Civil Engineers 91, SM3 (1965)

10. G. Leonards, Transactions of the American Society of Civil Engineers 120, 1421 (1955)

11. M. Mokhtari, M. Dehghani, Swell Shrink Behavior of Expansive Soils, Damage and Control (2012)

12. M.K. Gradhakrishnan, G.V.R. Prasada Raju, American Journal of Engineering Research (AJER) e-ISSN:2320-0847 (2014)

13. Tran Thi Thanh, Principles of using swelling-shrink soils for dam works in humid conditions in Vietnam. Ph.D. thesis (Polytechnic University, Ho Chi Minh City, 1998)

14. Vietnamese Standards: TCVN 8719:2012. Soils for hydraulic engineering construction - Laboratory test method for determination of expansion characteristics of soil (2012) 